Saudi Journal of Oral and Dental Research

Abbreviated Key Title: Saudi J Oral Dent Res

ISSN 2518-1300 (Print) | ISSN 2518-1297 (Online)

Scholars Middle East Publishers, Dubai, United Arab Emirates

Journal homepage: https://saudijournals.com

\title{
The Fit of Implant Framework a Literature Review
}

\author{
Mansour Saleh Alkanani $i^{*}$, Mazen Khalid Alnuwaiser ${ }^{2}$ \\ ${ }^{1}$ BDS, Ministry of Health, Riyadh, Saudi Arabia \\ ${ }^{2}$ BDS, College of Dentistry, King Saud University Riyadh, Saudi Arabia
}

DOI: $10.36348 /$ sjodr.2022.v07i01.007

| Received: 15.12.2021 | Accepted: 16.01.2022 | Published: 21.01.2022

*Corresponding author: Mansour Saleh Alkanani

BDS, Ministry of Health, Riyadh, Saudi Arabia

\section{Abstract}

Background/Aim: To date, there is no standard method to evaluate the fit of the implant framework. However, there are many proposed clinical and laboratory methods in the literature with varying accuracies based on numerous factors involved. Therefore, we conducted the current investigation to review the available evidence in the literature, comparing the available clinical as well as laboratory methods in assessing the fit of implant prostheses. Materials and Methods: We searched MEDLINE, PubMed, and Google Scholar databases for relevant studies related to the fit of the implant framework or the degree and effect of misfit. We also used the manual search method to search for any missing articles. Various combinations of key words were used to fit the searching guidelines of each database. Relevant studies of invitro and clinical design were included in this review. Results: The majority of the reviewed studies were either clinical or technique papers that proposed various strategies in detecting the fit of the implant framework, with a very limited number of clinical trials related to the topic. Multiple factors suggest that the concept 'passive fit' could be achieved in implant prosthodontics with the use of advances strategies. Various clinical and laboratory techniques in assessing the fit of the implant framework were identified. The advantages, drawbacks, and applicability of each technique are discussed. However, the applicability of these technique is clearly limited due to the absence of clinical trials (in vivo studies) assessing their validity and efficacy of such techniques. A slight misfit of the framework to the implant abutment/analogue was also observed in many of the investigated strategies. Conclusions: Due to the variations of techniques and the various parameters assessed by each, we suggest that it might be useful to combine several techniques to determine the accuracy of fit, quantify the effect and degree of misfit, and subsequently estimate the acceptable level of fit, using the reference system for each technique used accordingly.

Keywords: Implant Framework, passive fit, dental implants and bone.

Copyright $\odot 2022$ The Author(s): This is an open-access article distributed under the terms of the Creative Commons Attribution 4.0 International License (CC BY-NC 4.0) which permits unrestricted use, distribution, and reproduction in any medium for non-commercial use provided the original author and source are credited.

\section{FIT OF THE FRAMEWORK}

The need for passive fit

Osseointegrated implants have significantly different clinical mobility as compared to natural teeth. It was found that the mobility range for osseointegrated implant 17 to $58 \mu \mathrm{m}$ labially and 17 to $66 \mu \mathrm{m}$ lingually with loads of $2.0 \mathrm{~kg}$ which is caused by bone deformation. This is in contrast with natural teeth where mobility ranges from 100 to $200 \mu \mathrm{m}$ [1].

Due to the rigid connection between dental implants and bone, stresses caused by framework misfit will not dissipate over time. Some publications have stressed the importance of achieving a passive fit of implant frameworks because of this rigid connection $[2]$.

\section{Passive fit definition}

Passive fit is assumed to be one of the important prerequisites to maintain bone level around the implants. Theoretically, passive fit is defined as simultaneous and even contact between the whole inner surface of all retainers with all abutments without inducing any strain on the supporting implant components and surrounding bone structure in the absence of occlusal loads. Despite advancements in dental technology, passive fit as defined previously has not yet been achieved [3].

Many authors have defined acceptable passive fit but these definitions are hypothetical and are not based on scientific evidence. Branemark was the first one to define passive fit. He suggested that it should be 
at the level of $10 \mu \mathrm{m}$ to allow bone maturation and remodeling under occlusal loads [2]. Jemt suggested that the framework is considered to have a passive fit when the gap between framework and abutment is less than $150 \mu \mathrm{m}$. He also stated that when more than a half turn is needed to completely seat the screw after initial resistance was felt, the framework is considered to have poor fit [4]. Patterson defined passive fit as the absence of gap between framework and abutment and absence of unfavorable strain after torqueing the screws [5]. Karel et al., defined passive fit as an absolute lack of strain development after placement of framework [6]. Klineberg and Murray used precision metal shims of 30 $\mu \mathrm{m}$ thickness to evaluate the fit of the framework. They considered frameworks with a gap greater than $30 \mu \mathrm{m}$ over $10 \%$ of the circumference of the interface as unacceptable [7].

\section{Outcomes of framework misfit}

Due to the rigidity of the connection between osseointegrated implants and surrounding bone, any stress caused by framework misfit will be transmitted to implant components and implant bone interface [3].

A finite element study showed that the presence of $111 \mu \mathrm{m}$ vertical gap had a significant impact on stress distribution in implant components and surrounding bone. The presence of a cantilever or excessive force increased the effect of the misfit. When passive fit is achieved a lower peak stress is produced in each component due to widely distributed stress in all components. Also, when the prosthesis has a misfit, the gold screw and the abutment screw bore more stress than when a passive fit is present [8].

When the concept of implant osseointegration was established it was thought that having poor fit will have a detrimental effect on established osseointegrated implants [2]. In an animal study done by Carr et al., they found no difference in bone response between screw retained prostheses with two levels of misfits; 38 $\mu \mathrm{m}$ and $345 \mu \mathrm{m}$ in the absence of occlusal loading [9]. In a retrospective study done by Kallus et al., they examined 236 patients who were wearing an implantsupported prosthesis for at least 5 years. It was found that gold screw loosening was related to framework misfit. There were no clinical or radiographic findings that would indicate framework misfit will cause bone loss around implants [10]. Jemt and Book measured in vivo framework misfit in two groups of patients. One group was prospectively followed for one year, and the second group was followed retrospectively for five years. They found no statistical correlation between marginal bone loss and framework misfit with an average gap of $111 \mu \mathrm{m}$ for one year group and $91 \mu \mathrm{m}$ for the five year group and with a maximal discrepancy of $275 \mu \mathrm{m}$ for both groups [11].

Previous studies have indicated the presence of bone tolerance around implants. However, no studies have scientifically measured or quantified the amount of this tolerance [12]. Several publications suggest that poor implant framework fit may cause mechanical complications such as gold screw loosening or fracture, abutment screw fracture, and framework or veneering material fracture $[10,13,14]$. When the framework misfit is excessively large, external stresses will be introduced in screws and implant abutments which may lead to loosening or fracture of screws or fracture of the framework if it does not possess enough bulk. The loosening of the screws is attributed to inadequate counteracting torque to the bending of a poor-fitting framework when tightened to the implant abutment [3].

\section{MEASUREMENT OF THE FRAMEWORK MISFIT}

\section{Clinical Assessment}

Different methods have been proposed to evaluate the fit of the framework. Clinically there are different methods to evaluate the fit of the framework; however, none of these methods is accepted as the standard test. The accuracy of these methods can be affected by implant distribution and number, margin location, framework rigidity, eyesight, lighting, angle of vision, and experience of the dentist [12].

The alternate finger pressure technique is a simple technique to detect a gross misfit by applying pressure in an apical direction alternatively at each end of the framework to detect the presence of any fulcrum [15]. Adell et al., suggested that the observation of saliva movement at the framework-abutment junction increases the accuracy of this technique [16]. Direct vision and tactile sensation, with the use of an explorer is another technique that can be improved by the use of ample lighting and magnification [14, 15, 17]. Sensitivity of this method is affected by the size of the explorer tip, location of margin, and the dentist's visual acuity. Christensen showed that clinicians would accept a subgingival margin with an opening up to $119 \mu \mathrm{m}$, while supragingival with a $26 \mu \mathrm{m}$ opening were rejected [18]. Dental explorers are more efficient in detecting horizontal gaps compared to vertical ones [19].

Periapical radiographs are another method to evaluate framework fit especially when connections are subgingival. The radiographic film should be perpendicular to the long axis of the implant-abutment junction [20].

The one screw test was suggested by Jemt for evaluation of framework fit. [4] In this test, one screw is tightened at one terminal abutment and any discrepancy is observed at the other abutments [21, 22]. It is effective for long span frameworks. It is used in conjunction with direct vision and an explorer when the margins are supragingival or with radiograph for subgingival margins. One of its drawbacks is that it cannot detect discrepancies in three dimensions and often distortion is masked if it is occurs in a horizontal 
plane [21, 22]. Another screw test introduced by Jemt is based upon a vertical misfit of $150 \mu \mathrm{m}$ or less. In this test, every gold screw is tightened individually until initial finger resistance is achieved. If more than a half turn is needed to torque the gold screw from 10 to $15 \mathrm{~N}$ $\mathrm{cm}$ then it is a misfit $[23,24]$.

Disclosing materials, such as wax, elastomeric material, and pressure indicating paste have been used to evaluate framework fit $[17,25]$. They can be used with both supragingival and subgingival margins. Materials of measurable thickness like unwaxed floss $(12 \mu \mathrm{m})$ and shim stock $(10-12 \mu \mathrm{m})$ can also be used to assess the fit of the framework [12].

\section{Laboratory Assessment}

When the framework is fabricated, the lab technician should check the fit on the cast before the dentist tries it in the patient's mouth. A framework that does not fit the master cast will not fit in the mouth. Several different methods may be used to assess the fit of framework in the laboratory. Few of them are practical and cannot be used in a commercial laboratory.

One screw test: if no detectable gap exists between the implant analogs and the framework when one screw in the distal abutment is completely tightened we can say the framework has an acceptable fit. The presence or absence of the gap can be assessed by explorer, direct vision, micrometer, or magnification [26].

Microscope measurements: microscopes of different magnifying powers can be used to measure inter-implant distances or to measure vertical gaps in conjunction with one screw test. To use this method effectively reference points should be used to standardize measurement [27].

Photogrammetric technique: it was introduced by Lie and Jemt to analyze the fit of implant frameworks. This technique measures the three dimensional orientation of the abutment cylinders on the implant analogs. It involves the use of a small standard camera with a wide angle lens modified by placing a glass plate with cross mark in the film plane and two parallel mirrors in the front of the lens. This modification will result in the production of 3 images of every object from one exposure. The images produced by this camera will be measured by an analytic plotter under stereoscopic vision and with the aid of computer software. This technique can provide an accurate threedimensional measurement that can measure a gap as small as $30 \mu \mathrm{m}$. It is a technique sensitive procedure that requires standardization of the position of the camera [23].

Coordinate measuring machine: this machine consists of a probe which can travel in the $\mathrm{x}, \mathrm{y}, \mathrm{z}$ axes and record the dimension of the framework or interimplant analogue distances and height when it touches a surface. The distances that the probe travels is calculated by computer software and transformed into measurable data. When using this machine to measure framework misfit it is important to have a verifiable datum and a coordinate reference system before any comparison between different measurement sets [28]. Although this machine has high accuracy, it is not feasible to use this machine due to its high cost which make its use limited to dedicated metrology oriented research laboratories [26].

Strain gauge analysis: strain gauges consist of fine wires or foils arranged in a grid pattern which are attached to the framework. These gauges are sensitive to strains caused by inaccuracy of framework misfits. One of the drawbacks of this method is that strain values are measured only where the gauges are attached, which make detection of strain dependent on where the gauges are attached and not where the highest strain is. They are also sensitive to temperature [29].

Finite element analysis (FEA): is a computerbased technique for calculating strength and behavior of structures [30]. It is a good tool to evaluate the behavior of peri-implant structure and stresses affecting screws and implant bone interface caused by framework fitting and occlusal loading. The clinical significance of the information provided by the FEA is dependent on the assumptions and boundary conditions in the hypothesized model [26].

\section{FACTORS AFFECTING THE FRAMEWORK FIT ACCURACY}

Each step for framework fabrication has an effect on the final fit of the framework starting from impression making. Clinical factors include impression material and impression technique, while laboratory factors include die material, die fabrication technique, and materials and techniques used to fabricate the framework.

\section{Impression Material}

Impression materials are used to record a negative form of the intraoral structure for the fabrication of stone casts that replicate the intraoral structure where the prosthesis is fabricated. The accuracy of the impression is very important for the construction and the fit of the implant-supported prosthesis. Ideal dental implant impression should produce an accurate impression, resist tearing without traumatic removal, has enough working time, sets within a reasonable time, biocompatible, pleasant order, taste and acceptable color, easy to use, easily wets oral tissue, dimensionally stable, compatible with die materials, and have enough rigidity to prevent displacement or rotation of impression coping [31]. 
Alginate impression material are hydrophilic in nature and has the ability to work in wet environments with blood or saliva with good accuracy. It can reproduce good surface details as it has a low wetting angle. It can be easily removed from the patient's mouth. Due to its lack of rigidity, alginate impressions must be supported by rigid trays. Alginate can be considered as the most flexible impression material which makes it not useful for dental implant impression. It is relatively low in cost compared to other impression materials. Alginate impression materials are dimensionally unstable, asimbibition or desication can occur therefore alginate must be poured no more than 10-12 minutes after impression making and it can only be poured once. It has relatively a low tear strength therefore it can tear easily [31].

Polyether impression materials are moderately hydrophilic, have low wetting angle, accurate, dimensionally stable, and can be poured after 1-2 weeks after impression making and allows multiple pours. Polyethers have the highest tear strength therefore it does not tear easily and can be used in subgingival areas. Polyethers are rigid materials therefore difficult to remove from the patient's mouth; however, "soft" polyethers can be removed more easily. It has a short working time (4-5 minutes) and setting is not altered by latex. Polyethers taste bad; however its bitter taste can be masked by flavors [31].

Polyvinyl siloxanes are hydrophobic in nature therefore less accurate in the presence of moisture; a surfactant might be needed to reduce the high wetting angle. They are dimensionally stable allowing for multiple pours and can be poured weeks after impression making, but require a wait of at least 30 minutes before pouring to allow the setting reaction to be completed to avoid porosity. They are rigid with high tear strength but not more than polyether; however, they can be removed more easily than polyethers. It is thermally sensitive, sets slower upon cooling and faster upon heating. Polyvinyl siloxanes can be contaminated by sulfur or sulfur compounds from latex gloves and rubber dams and from the oxygen inhibited layer found after curing resins [31].

Polysulfide impression materials are low to moderately hydrophilic, have low wetting angle with excellent details, fair dimensional stability can allow multiple pours only with the presence of acceptable thickness of the material, not rigid and can be removed easily without tearing therefore can reproduce the subgingival margin accurately. It is inexpensive, not affected by latex, has bitter taste and it cannot adhere to itself therefore cannot be used in border molding [31].

Impression plasters contains calcium sulfate hemihydrate as the main component. This material is rigid and cannot bend, and must be stored in an air tight container to prevent it from absorbing water from air.
Impression plasters are rarely used nowadays; however, it is used as "wash" material in edentulous impressions[32].

Polyether and vinylpolysiloxane (VPS) are the preferred impression material for implant impressions [33-37]. Wee et al., evaluated torque resistance of different impression materials and found that (medium consistency) polyether has the highest torque value followed by VPS addition silicone (high consistency) and then polysulfide (medium consistency). Additionally, he reported that implant casts made from polyether and addition silicone impression materials were more accurate than polysulfide impression material [33]. Assunaco et al., evaluated four dental impression materials using three different impression techniques with different implant angulation for model with four implants. They found that condensation silicone has the least accuracy among materials tested and he suggested that the use of condensation silicone is contraindicated with dental implants. They also found that polyether and high viscosity addition silicone were the most accurate. Polysulfide had an intermediate accuracy [38].

Several other studies compared the accuracy of polyether and VPS impression materials and found no difference [33-36, 38-40].

\section{Custom tray vs. stock tray:}

Multiple publications showed that custom trays consistently produced accurate impression compared with stock trays in prepared teeth. In dental implant impression Burns et al found that rigid custom trays for pick up impressions produced more accurate impressions compared with flexible stock tray. It was possible to have accurate impression with stock tray but its accuracy was not consistent compared to custom tray $[41,42]$.

\section{Impression technique}

There are two implant impressions techniques used with most implant systems. The closed-tray technique uses tapered impression coping. The copings are connected to the implants and after making the impression the copings are removed from the mouth, connected to an implant analogue and then reinserted into the impression before pouring the final cast. The open-tray technique uses square and screw-retained impression copings. The openings in the tray allow access to the impression coping screws so that the coping can be removed along with the impression.

Liou et al., evaluated the accuracy of replacing three tapered impression copings in a transfer impression technique made from Impregum $\mathrm{F}$ and Extrude impression materials. It was found that none of the copings were replaced accurately and consistently by all five participating dentists [34]. Daoudi et al., found significant difference in implant position in the 
horizontal plane, implant inclination and rotation in casts produced by senior dentist, postgraduate student and dental technicians after they repositioned tapered impression copings into elastomeric closed-tray impressions [37].

Del Acqua et al., reported in his study that both splinted and unsplinted open-tray impressions are more accurate compared with closed-tray impression. When there are three or less implants, most studies showed no difference between closed-tray and open tray impression techniques [43]. However, when there are four or more implants several studies have shown that open-tray impressions were more accurate [40]. Kim et al., compared the accuracy of implant impression in-vitro and found that the non-splinted technique showed less three dimensional linear displacements than the splinted technique during impression making while the splinted technique showed less three dimensional linear displacement than the nonsplinted group during cast fabrication [44]. One study evaluated the accuracy of pick-up impressions made with an acrylic resin splint and without on a model with four internal connection implants using polyether impression material. It was found that splinting impression copings with acrylic resin produced more accurate casts [45].

Assunaco et al., evaluated accuracy of transfer impressions for osseointegrated implants at various angulations. They evaluated four dental impression materials using three different impression techniques with different implant angulation situations for model with four implants. It was found that open tray impressions with splinted impression coping produced better results compared with open tray without splinting and closed tray impression [38]. More recent studies reported implant impression with splinted coping were more accurate than impressions made with non-splinted copings $[38,40,46]$.

\section{Die Materials}

A definitive cast is the positive reproduction of the intraoral structure recorded by the impression material. Desirable qualities of die materials are accuracy, dimensional stability, ability to reproduce fine details, strength, resistance to abrasion, ease of adaptation to the impression material, color for contrast, and safety [31].

Gypsum is the most commonly used cast and die material. It is produced by calcining calcium sulfate dihydrate. The dihydrate is ground and heated to temperature of $110^{\circ} \mathrm{C}$ to $120^{\circ} \mathrm{C}\left(230^{\circ} \mathrm{F}\right.$ to $\left.250^{\circ} \mathrm{F}\right)$ to drive off some of the water of crystallization and convert them to calcium sulfate hemihydrate. Depending upon heating conditions, different forms of calcium sulfate hemihydrate are produced [47].
According to the American Dental Association specification number 25 dental gypsum products are available in five types:

I. Plaster Impression.

II. Plaster Model.

III. Dental Stone, Model.

IV. Dental Stone, Die, High Strength, Low Expansion. V. Dental Stone, Die, High Strength, High Expansion.

The criteria used to classify types of gypsum products are setting expansion and compressive strength. All of these five types are made of the same chemical (calcium sulfate hemihydrate); however, the difference is in the amount of water remaining within the crystal. Water decreases as the temperature increases during the process of calcination [48].

After initial setting all gypsum products show measurable linear expansion this expansion could alter the positional relationship of implant replicas within the die material. American Dental Association Specification Number 25 defines setting expansion as percentage linear growth of the die material measured at two hours after initial mixing [48]. Heshmati et al., measured the linear setting expansion of six type IV and type $\mathrm{V}$ dental stones up to 120 hours. He found that for most of die materials, setting expansion was complete at 96 hours and most of the expansion happened after 2 hours $(22 \%$ to $71 \%$ of the total expansion). Die keen exhibited the highest total expansion [49].

One of the disadvantages of gypsum is poor resistance to abrasion. To compensate for this disadvantage attempts were made to improve gypsum by including hardener in the gypsum products. Resin strengthened gypsum products such as Resin Rock is an example of attempt to strengthen the gypsum products [50].

An alternative material to gypsum products are epoxy resin and electroplated dies. Epoxy resin die materials are used to overcome the low strength and poor abrasion resistance of die stone material. They exhibit polymerization shrinkage with values ranging from $0.1 \%$ to $0.3 \%$. It has better detail reproduction compared with gypsum [50]. Electroplated die involves the deposition of a coat of pure silver or copper on the impression and then the coat is supported with type IV stone or resin. This technique has many disadvantages, it is time consuming to produce a cast with this technique as it may take up to eight hours to pour the cast, special equipment is necessary, it is incompatible with many impression materials and when silver plating is used, and health safety is a concern because of the cyanide solution [50].

Wee et al., measured the dimensional changes of implant casts fabricated with Vel-Mix, Die Keen, Resin Rock and a low fusing alloy. He also measured the amount of strain produced in implant framework 
which was secured to different experimental stone casts. Resin rock produced the least mean absolute strain on the implant framework and it also produced the least dimensional change among other die stone materials [51].

Duke et al., compared the physical properties of two resin modified type IV gypsum die stone material (Resin Rock and Milstone), two conventional type IV gypsum die materials (Silky Rock and Diestone) and an epoxy resin die material (Epoxy-Die). Epoxy die had a superior abrasion resistance, better detail reproduction, the highest transverse strength and the highest dimensional change. There was no significance difference between the properties of resin modified gypsum die materials and those of conventional die materials [52].

Kenyon et al., compared the linear dimensional accuracy of seven die materials: type IV gypsum die (Vel-Mix), type $\mathrm{V}$ gypsum die (Hard Rock), resin reinforced type IV gypsum die ( Resin Rock), epoxy resin (Die Epoxy), polyurethane resin (Model Tech), bis-acryl composite material (Integrity) and copper-plated supported with resin reinforced type IV gypsum die. All measurements were done 96 hours after separation from the impression. Resin reinforced type IV gypsum die and copper plated dies were more dimensionally accurate than all others. Epoxy resin material shrank the same as gypsum expanded. Polyurethane dies showed combination shrinkage and expansion which prevents it from being recommended as a die material [53].

Linear expansion will affect the accuracy of the cast and hence the accuracy of the framework fit. All die material will exhibit some dimensional changes after setting. It is important that dentists and laboratory technicians select a die material with minimal dimensional changes for implant restorations.

\section{Implant framework fabrication technique:}

Conventional casting:

The fit of a cast implant framework is affected by pattern fabrication material, investment material, investing technique and casting [54]. Noble metal alloys produce implant frameworks with better fit compared to base metals. Frameworks cast using a gold alloy has the most accurate fit among alloys, but the high cost of gold limits it use. Silver-palladium alloy is an economical alternative to gold and it has superior fit compared with base metal [55]. Noble alloys have a high density and low solidus temperature compared to base alloys which make them more easily castable. In addition, cast-to abutments can be only used with noble alloys. Cast-to abutments have a prefabricated machined surface that fits more accurately compared to burn out plastic sleeves used with base metals [56].
Base metal alloys such as cobalt-chrome (Co$\mathrm{Cr})$ and nickel-chrome (Ni-Cr) are less expensive compared with noble alloys and have superior physical properties. However, they are difficult to cast, finish, and polish. For base metal casting accuracy, titanium (Ti) alloy casting is more accurate than $\mathrm{Ni}-\mathrm{Cr}$ and $\mathrm{Co}-$ $\mathrm{Cr}$ alloys, and $\mathrm{Co}-\mathrm{Cr}$ alloy casting is worse than $\mathrm{Ni}-\mathrm{Cr}$. Single base alloy casting are not acceptable for implant frameworks and additional refinements to improve their fit are needed before they can be inserted [55].

Sectioning and soldering is one way to improve the fit of cast frameworks, especially for noble alloys. The framework may be cast in multiple segments and then soldered together with the use of intraoral index [57]. The cast-to procedure is a modification of soldering technique where instead of using low fusing solder to connect the framework segments a similar framework alloy is used to connect the segments together. The cast-to method can be superior to the normal soldering technique [58].

Laser welding is another technique to connect framework segments. It is an efficient method to improve the fit of base metal alloy frameworks. It doesn't require the use of additional materials to connect the framework thus in theory it should not reduce the strength of the welded structure. However a 15 years retrospective study reported more fractures in laser welded frameworks compared to gold framework and all fractures happened in the laser welded joint [59].

Spark erosion also known as electric discharge machining is a process that uses electric discharge to precisely contour metal or alloy by erosion [57]. Spark erosion can provide superior fit compared to sectioning and soldering gold alloy frameworks. It improves the fit of base metal alloy frameworks more than it improves the ones with noble alloy. It can be used on the framework even after porcelain application; however, it requires a special machine and training and it is an expensive procedure which hindered its universal use in commercial labs [55].

Computer aided design and computer aided manufacture (CAD/CAM):

CAD/CAM involves three steps, 1) scanning to record the $3 \mathrm{D}$ geometry of the dental cast and construct a virtual model; 2) CAD modeling by virtually design the $3 \mathrm{D}$ contours of implant framework, and 3) CAM production by milling the actual framework according to the virtual design [60]. Advantages of CAD/CAM fabrication process is it eliminates the use of wax patterns, investment and casting, and any inaccuracies that comes with these steps. In addition, CAD/CAM titanium frameworks are milled from homogeneous blocks. They have better physical properties and the process is less labor intensive compared to conventional cast alloy [61] CAD/CAM milled frameworks exhibit a superior and 
consistent fit compared with conventional cast frameworks even with sectioning and laser welding [55, 62]. Until now CAD/CAM milled frameworks fabrication are the most accurate and consistent way to fabricate implant frameworks [55].

\section{VERIFYING THE ACCURACY OF THE MASTER CAST:}

Henry and Rasmussen described techniques to verify the accuracy of the master cast using a verification jig made of Duralay resin [15, 63]. Moreover, verification jigs can be used for fabrication of a corrected cast if the master cast was not accurate $[15,64]$, or it can be used to verify the fit of the metal framework $[15,65]$.

One in vitro study compared the accuracy of verification jigs to closed and open tray impression technique with elastomeric impression material. The model used in this study was of 3 parallel implants. It was found that there was no positive advantage for using a verification jig since the accuracy of verification jigs was not significantly superior to standard impression techniques [66].

In a retrospective study done by Ercoli et al; he evaluated if there was a difference in the passivity between metal frameworks fabricated with or without a verification jigs, it was found that when a verification jig was used all frameworks achieved passive fit on all patients. While in the other group, where the frameworks were fabricated without a verification jig, only 2 frameworks achieved passive fit while 12 did not [67].

\section{BIBLIOGRAPHY}

1. Kim, Y., Oh, T. J., Misch, C. E., \& Wang, H. L. (2005). Occlusal considerations in implant therapy: clinical guidelines with biomechanical rationale. Clinical oral implants research, 16(1), 26-35.

2. Branemark, P. I. (1983). Osseointegration and its experimental background. J prosthet Dent, 50, 399410.

3. Sahin, S., \& Çehreli, M. C. (2001). The significance of passive framework fit in implant prosthodontics: current status. Implant dentistry, 10(2), 85-92.

4. Jemt, T. (1991). Failures and complications in 391 consecutively inserted fixed prostheses supported by Brånemark implants in edentulous jaws: a study of treatment from the time of prosthesis placement to the first annual checkup. International Journal of Oral \& Maxillofacial Implants, 6(3), 270-276.

5. Watanabe, F., Uno, I., Hata, Y., Neuendorff, G., \& Kirsch, A. (2000). Analysis of stress distribution in a screw-retained implant prosthesis. International Journal of Oral \& Maxillofacial Implants, 15(2), 209-218.
6. Karl, M., Winter, W., Taylor, T. D., \& Heckmann, S. M. (2004). In vitro study on passive fit in implant-supported 5-unit fixed partial dentures. International Journal of Oral \& Maxillofacial Implants, 19(1), 30-37.

7. Klineberg, I. J., \& Murray, G. M. (1985). Design of superstructures for osseointegrated fixtures. Swedish dental journal. Supplement, 28, 63-69.

8. Kunavisarut, C., Lang, L. A., Stoner, B. R., \& Felton, D. A. (2002). Finite element analysis on dental implant-supported prostheses without passive fit. Journal of Prosthodontics, 11(1), 30-40.

9. Carr, A. B., Gerard, D. A., \& Larsen, P. E. (1996). The response of bone in primates around unloaded dental implants supporting prostheses with different levels of fit. The Journal of prosthetic dentistry, 76(5), 500-509.

10. Kallus, T., \& Bessing, C. (1994). Loose gold screws frequently occur in full-arch fixed prostheses supported by osseointegrated implants after 5 years. International Journal of Oral \& Maxillofacial Implants, 9(2), 169-178.

11. Jemt, T., \& Book, K. (1996). Prosthesis misfit and marginal bone loss in edentulous implant patients. International Journal of Oral \& Maxillofacial Implants, 11(5), 620-625.

12. Kan, J. Y., Rungcharassaeng, K., Bohsali, K., Goodacre, C. J., \& Lang, B. R. (1999). Clinical methods for evaluating implant framework fit. The Journal of prosthetic dentistry, 81(1), 7-13.

13. Jemt, T., Lindén, B., \& Lekholm, U. (1992). Failures and complications in 127 consecutively placed fixed partial prostheses supported by Brånemark implants: from prosthetic treatment to first annual checkup. International Journal of Oral \& Maxillofacial Implants, 7(1), 40-44.

14. Sones, A. D. (1989). Complications with osseointegrated implants. The Journal of prosthetic dentistry, 62(5), 581-585.

15. Henry, P. J. (1987). An alternative method for the production of accurate casts and occlusal records in osseointegrated implant rehabilitation. The Journal of prosthetic dentistry, 58(6), 694-697.

16. Adell, R., Eriksson, B., Lekholm, U., Brånemark, P. I., \& Jemt, T. (1990). A long-term follow-up study of osseointegrated implants in the treatment of totally edentulous jaws. International Journal of Oral \& Maxillofacial Implants, 5(4), 347-359.

17. Loos, L. G. (1986). A fixed prosthodontic technique for mandibular osseointegrated titanium implants. The Journal of prosthetic dentistry, 55(2), 232-242.

18. Christensen, G. J. (1966). Marginal fit of gold inlay castings. The Journal of prosthetic dentistry, 16(2), 297-305.

19. Hayashi, M., Wilson, N. H. F., Ebisu, S., \& Watts, D. C. (2005). Influence of explorer tip diameter in identifying restoration margin discrepancies. Journal of dentistry, 33(8), 669-674. 
20. Cox, J. F., \& Pharoah, M. (1986). An alternative holder for radiographic evaluation of tissueintegrated prostheses. J Prosthet Dent, 56(3), 338341.

21. Eisenmann, E., Mokabberi, A., Walter, M. H., \& Freesmeyer, W. B. (2004). Improving the fit of implant-supported superstructures using the spark erosion technique. International Journal of Oral \& Maxillofacial Implants, 19(6), 810-818.

22. Tan, K. B., Rubenstein, J. E., Nicholls, J. I., \& Yuodelis, R. A. (1993). Three-dimensional analysis of the casting accuracy of one-piece, osseointegrated implant-retained prostheses. International Journal of Prosthodontics, 6(4), 346-363.

23. Jemt, T., \& Lie, A. (1995). Accuracy of implantsupported prostheses in the edentulous jaw. Analysis of precision of fit between cast gold-alloy frameworks and master casts by means of a threedimensional photogrammetric technique. Clinical oral implants research, 6(3), 172-180.

24. Jemt, T. (1994). Fixed implant-supported prostheses in the edentulous maxilla. A five-year follow-up report. Clinical oral implants research, 5(3), 142-147.

25. Goll, G. E. (1991). Production of accurately fitting full-arch implant frameworks: part I-clinical procedures. The Journal of prosthetic dentistry, 66(3), 377-384.

26. Abduo, J., Bennani, V., Waddell, N., Lyons, K., \& Swain, M. (2010). Assessing the fit of implant fixed prostheses: a critical review. International Journal of Oral \& Maxillofacial Implants, 25(3), 506-515.

27. de Mattias Sartori, I. A., Ribeiro, R. F., Francischone, C. E., \& de Mattos, M. D. G. C. (2004). In vitro comparative analysis of the fit of gold alloy or commercially pure titanium implantsupported prostheses before and after electroerosion. The Journal of prosthetic dentistry, 92(2), 132-138.

28. Mulcahy, C., Sherriff, M., Walter, J. D., \& Fenlon, M. R. (2000). Measurement of misfit at the implant-prosthesis interface: an experimental method using a coordinate measuring machine. International Journal of Oral \& Maxillofacial Implants, 15(1), 111-118.

29. Brosh, T., Pilo, R., \& Sudai, D. (1998). The influence of abutment angulation on strains and stresses along the implant/bone interface: comparison between two experimental techniques. The Journal of prosthetic dentistry, 79(3), 328-334.

30. Shetty, P., Hegde, A., \& Rai, K. (2010). Finite element method-an effective research tool for dentistry. Journal of Clinical Pediatric Dentistry, 34(3), 281-285.

31. Sakaguchi, R. L. (2006). Craig's restorative dental materials. Mosby Elsevier,.
32. O'Brien, W. J. (Ed.). (2002). Dental materials and their selection.

33. Wee, A. G. (2000). Comparison of impression materials for direct multi-implant impressions. The Journal of prosthetic dentistry, 83(3), 323-331.

34. Liou, A. D., Nicholls, J. I., Yuodelis, R. A., \& Brudvik, J. S. (1993). Accuracy of replacing three tapered transfer impression copings in two elastomeric impression materials. International Journal of Prosthodontics, 6(4), 377-83.

35. Lorenzoni, M., Pertl, C., Penkner, K., Polansky, R., Sedaj, B., \& Wegscheider, W. A. (2000). Comparison of the transfer precision of three different impression materials in combination with transfer caps for the Frialit ${ }^{\circledR}-2$ system. Journal of oral rehabilitation, 27(7), 629-638.

36. Barrett, M. G., de Rijk, W. G., \& Burgess, J. O. (1993). The accuracy of six impression techniques for osseointegrated implants. Journal of Prosthodontics, 2(2), 75-82.

37. Daoudi, M., Setchell, D. J., \& Searson, L. J. (2001). A laboratory investigation of the accuracy of two impression techniques for single-tooth implants. International Journal of Prosthodontics, 14(2), 152-158.

38. Assuncao, W. G., Gennari Filho, H., \& Zaniquelli, O. (2004). Evaluation of transfer impressions for osseointegrated implants at various angulations. Implant dentistry, 13(4), 358-366.

39. Wenz, H., Reuter, H., \& Hertrampf, K. (2008). Accuracy of impressions and casts using different implant impression techniques in a multi-implant system with an internal hex connection. International Journal of Oral and Maxillofacial Implants, 23(1), 39-47.

40. Lee, H., So, J. S., Hochstedler, J. L., \& Ercoli, C. (2008). The accuracy of implant impressions: a systematic review. The Journal of prosthetic dentistry, 100(4), 285-291.

41. Burns, J., Palmer, R., Howe, L., \& Wilson, R. (2003). Accuracy of open tray implant impressions: an in vitro comparison of stock versus custom trays. The Journal of prosthetic dentistry, 89(3), 250-255.

42. Gordon, G. E., Johnson, G. H., \& Drennon, D. G. (1990). The effect of tray selection on the accuracy of elastomeric impression materials. The Journal of prosthetic dentistry, 63(1), 12-15.

43. Del'Acqua, M. A., Arioli-Filho, J. N., \& Compagnoni, M. A. (2008). Accuracy of impression and pouring techniques for an implantsupported prosthesis. International Journal of Oral \& Maxillofacial Implants, 23(2), 226-236.

44. Kim, S., Nicholls, J. I., Han, C. H., \& Lee, K. W. (2006). Displacement of implant components from impressions to definitive casts. International Journal of Oral \& Maxillofacial Implants, 21(5), 747-755.

45. Vigolo, P., Fonzi, F., Majzoub, Z., \& Cordioli, G. (2004). An evaluation of impression techniques for 
Mansour Saleh Alkanani \& Mazen Khalid Alnuwaiser; Saudi J Oral Dent Res, Jan 2022; 7(1): 31-39

multiple internal connection implant prostheses. The Journal of prosthetic dentistry, 92(5), 470-476.

46. Cabral, L. M., \& Guedes, C. G. (2007). Comparative analysis of 4 impression techniques for implants. Implant dentistry, 16(2), 187-194.

47. Anusavice, K. J., Shen, C., \& Rawls, H. R. (Eds.). (2012). Phillips' science of dental materials. Elsevier Health Sciences.

48. New American Dental Association Specification No. 25 for dental gypsum products. J Am Dent Assoc, 1972, 84(3), 640-644.

49. Heshmati, R. H., Nagy, W. W., Wirth, C. G., \& Dhuru, V. B. (2002). Delayed linear expansion of improved dental stone. The journal of prosthetic dentistry, 88(1), 26-31.

50. Rosenstiel, S., Land, M., \& Fujimoto, J. (2006). Implant Supported Prosthesis. Contemporary Fixed Prosthodontics, Mosby Elsevier.

51. Wee, A. G., Schneider, R. L., Aquilino, S. A., Huff, T. L., Lindquist, T. J., \& Williamson, D. L. (1998). Evaluation of the accuracy of solid implant casts. Journal of Prosthodontics, 7(3), 161-169.

52. Duke, P., Moore, B. K., Haug, S. P., \& Andres, C. J. (2000). Study of the physical properties of type IV gypsum, resin-containing, and epoxy die materials. The Journal of prosthetic dentistry, 83(4), 466-473.

53. Kenyon, B. J., Hagge, M. S., Leknius, C., Daniels, W. C., \& Weed, S. T. (2005). Dimensional accuracy of 7 die materials. Journal of Prosthodontics: Implant, Esthetic and Reconstructive Dentistry, 14(1), 25-31.

54. Michalakis, K. X., Hirayama, H., \& Garefis, P. D. (2003). Cement-retained versus screw-retained implant restorations: a critical review. International journal of oral \& maxillofacial implants, 18(5), 719-728.

55. Abduo, J., Lyons, K., Bennani, V., Waddell, N., \& Swain, M. (2011). Fit of screw-retained fixed implant frameworks fabricated by different methods: a systematic review. International Journal of Prosthodontics, 24(3), 207-220.

56. Carr, A. B., Brunski, J. B., \& Hurley, E. (1996). Effects of Fabrication, Finishing, and Polishing Procedures on Preload in Prostheses Using Conventional'Gold'and Plastic Cylinders. International Journal of Oral \& Maxillofacial Implants, 11(5), 589-598.

57. Wee, A. G., Aquilino, S. A., \& Schneider, R. L. (1999). Strategies to achieve fit in implant prosthodontics: a review of the literature. International Journal of

Prosthodontics, 12(2), 167-178.

58. Romero, G. G., Engelmeier, R., Powers, J. M., \& Canterbury, A. A. (2000). Accuracy of three corrective techniques for implant bar fabrication. The Journal of prosthetic dentistry, 84(6), 602-607.

59. Örtorp, A., \& Jemt, T. (2009). Early laser-welded titanium frameworks supported by implants in the edentulous mandible: a 15-year comparative follow-up study. Clinical implant dentistry and related research, 11(4), 311-322.

60. Abduo, J., \& Lyons, K. (2013). Rationale for the use of CAD/CAM technology in implant prosthodontics. International journal of dentistry, 2013, 768121.

61. Drago, C., \& Howell, K. (2012). Concepts for designing and fabricating metal implant frameworks for hybrid implant prostheses. Journal of Prosthodontics: Implant, Esthetic and Reconstructive Dentistry, 21(5), 413-424.

62. Paniz, G., Stellini, E., Meneghello, R., Cerardi, A., Gobbato, E. A., \& Bressan, E. (2013). The precision of fit of cast and milled full-arch implantsupported restorations. International Journal of Oral \& Maxillofacial Implants, 28(3), 687-693.

63. Rasmussen, E. J. (1987). Alternative prosthodontic technique for tissue-integrated prostheses. The Journal of prosthetic dentistry, 57(2), 198-204.

64. McCartney, J. W., \& Pearson, R. (1994). Segmental framework matrix: master cast verification, corrected cast guide, and analog transfer template for implant-supported prostheses. Journal of Prosthetic Dentistry, 71(2), 197-200.

65. Hebel, K. S., Galindo, D., \& Gajjar, R. C. (2000). Implant position record and implant position cast: minimizing errors, procedures and patient visits in the fabrication of the milled-bar prosthesis. The Journal of prosthetic dentistry, 83(1), 107-116.

66. Jorge, E., Funkenbusch, P. D., Ercoli, C., Moss, M. E., Graser, G. N., \& Tallents, R. H. (2002). Verification jig for implant-supported prostheses: A comparison of standard impressions with verification jigs made of different materials. The Journal of prosthetic dentistry, 88(3), 329-336.

67. Ercoli, C., Geminiani, A., Feng, C., \& Lee, H. (2012). The influence of verification jig on framework fit for nonsegmented fixed implantsupported complete denture. Clinical implant dentistry and related research, 14, e188-e195. 